\title{
CONSIDERAÇÕES SOBRE ANÁLISE ECONÔMICA DO DIREITO E A EFETIVIDADE: DIREITO FUNDAMENTAL À SAÚDE NO BRASIL
}

\author{
Daniela Vieira de Melo ${ }^{276}$
}

Recebido em: 19/05/2016

Aprovado em: 25/07/2016

\section{RESUMO}

Este artigo tem como objetivo principal analisar quais seriam os meios para garantir a efetividade do Direito Fundamental à saúde no Estado Democrático de Direito Brasileiro. Como os Direitos sociais prestacionais à saúde são concretizados de acordo com os valores constitucionais vigentes? Mais do que a mera limitação do poder político, o constitucionalismo garante uma feição axiológica aos direitos, conferindo lhes fundamentalidade material e tendo como norte primeiro a dignidade da pessoa humana. $\mathrm{O}$ presente estudo ainda se detém à pormenorização do Direito à Saúde. Quais são suas características essenciais de estruturação e funcionamento? A criação do Sistema Único de Saúde favoreceu a implementação de um sistema de saúde igualitário, não contributivo e de acesso Universal. Essa tarefa audaciosa exige uma série de instrumentos normativos, judiciais e extrajudiciais para realizar-se. A garantia de efetividade desse direito exige prestações positivas do Estado e a consequente implementação das políticas públicas devidas, no entanto, existem alguns limites, dentre eles destacam-se, principalmente, o de ordem orçamentária, que devem ser avaliados. O custo social e econômico destas demandas e também a possibilidade de aplicação de soluções cooperativas e judiciais são pontos chaves para o atendimento das necessidades dos destinatários do sistema de saúde. A Análise Econômica do Direito também serve de fundamento para a busca da concretização e efetividade deste Direito.

Palavras-chave: Direito à Saúde. Análise Econômica Do Direito. Dignidade Da Pessoa Humana. Efetividade.

\section{INTRODUÇÃO}

\footnotetext{
276 Servidora Pública no Tribunal de Justiça do Estado da Bahia. Mestranda em Direito Público pela Universidade Federal da Bahia (UFBA). Especialista em Direito Público pela Universidade Anhanguera/Faculdade Baiana de Direito. Graduação em Direito pela Universidade Estadual de Feira de Santana- UEFS. Endereço eletrônico: danielavieira.adv@hotmail.com.
} 
O presente trabalho por escopo precípuo discutir como garantir maior efetividade ao Direito prestacional à Saúde que compõe o extenso rol de direitos fundamentais do cidadão previstos na Constituição Federal. A despeito de parecer uma constatação simples, é preciso ter cuidado, porquanto a essencialidade e complexidade desse direito fundamental exigem mais do que a mera positivação na Carta Constitucional. É imperativa a sua efetividade.

$\mathrm{O}$ art. 5, caput, da Constituição consagra o direito à vida como direito fundamental pertencente a toda e qualquer pessoa. É direito essencial, pois a partir dele, uma série de outros direitos pode realizar-se. A dignidade da pessoa humana consiste no elemento qualificativo de tal direito, conferindo-lhe, portanto, todas as condições ideais de seu pleno gozo.

Não é por outra razão- senão a de realização de uma vida digna- que o direito à saúde, guarda estreita relação com o direito à vida. As condições de dignidade de vida se concretizam, dentre outras formas, pela realização, promoção, atendimento e efetivação de ações e serviços ligados à saúde. Por isso é tão imperativa e urgente a discussão e amadurecimento a respeito do tema.

O Poder Público, através da implementação das diversas políticas sociais, assume compromissos que visam atender as necessidades dos indivíduos e equalizar interesses públicos, compatibilizando-os com as disponibilidades orçamentárias. Tradicionalmente tais questões estão adstritas ao Poder Executivo. Em que pese afirmar que, no entanto, deve haver ampliação do rol de poderes legitimados para a garantia de efetividade dos direitos sociais.

É nesse sentido que este trabalho também pretende tratar a respeito do Poder Judiciário com a sua influência nas decisões políticas relativas ao Direito Fundamental à saúde. De modo que, as deficiências na execução dos compromissos públicos assumidos esbarram em questões como inefetividade das políticas adotadas, insuficiência de recursos, insatisfações que chegam ao Judiciário em forma de demandas.

\section{A IMPORTÂNCIA DA ANÁLISE ECONÔMICA DO DIREITO E O CUSTO DO DIREITO À SAÚDE NO BRASIL}

Importantes estudos de doutrinas que relacionam os métodos econômicos à teoria social surgiram na década de 90, tendo em vista, em linhas gerais, garantir maior eficiência no trato de problemas importantes. Como foi com a teoria econômica sendo aplicada ao Direito. E nessa linha de percepção que muitos autores abordam sobre o uso mais racional de dinheiro publico 
para garantia de direitos, através de estudos econômicos, ou melhor, da Análise Econômica do Direito (AED) ou Economia do Direito.

A economia do direito pode ser definida de forma simples como a aplicação da teoria econômica (principalmente a teoria dos preços) e dos métodos estatísticos ao estudo da formação, estrutura, processos e impacto da lei e das instituições jurídicas. Em que pese ainda não haver exato consenso sobre sua definição, na última década, esse novo campo de estudo alcançou o status de uma disciplina diferenciada com seus especialistas, e suas próprias revistas e livros, o que indicaria um crescente interesse sobre o assunto (VELJANOVSKI, 1994: 21).

É imprescindível notar que existiu, inicialmente, uma dificuldade de se relacionar saberes distintos, tendo em vista que os métodos adotados por cada uma das áreas seriam de diferentes ordens.

Enquanto o Direito é exclusivamente verbal, a Economia é também matemática; enquanto o Direito é marcadamente hermenêutico, a Economia é marcadamente empírica; enquanto o Direito aspira ser justo, a Economia aspira ser científica; enquanto a crítica econômica se dá pelo custo, a crítica jurídica se dá pela legalidade.Isso torna o diálogo entre economistas e juristas inevitavelmente turbulento, e geralmente bastante destrutivo( SALAMA, 2008).

Todavia, tais dificuldades não se consideram como impossibilidades de relacionamento entre as disciplinas. Isso está demonstrado com as obras de diversos autores como Cento Veljanovski que relaciona a economia, o Direito e a Lei; Ronald Coase que trata do problema do Custo Social; Sustein e Holmes e o custo dos direitos; Richard Posner da Universidade de Chicago; entre tantos outros.

Por óbvio que a Análise Econômica do Direito não está imune a críticas e nem deve ser abordada como única solução. Este estudo pretende expor a análise econômica do direito como forma de reflexão sobre o problema, pretendendo sugerir possíveis soluções, sem querer esgotálas.

Neste contexto, a excelência da obra de Sustein Causs e Holmes deve ser citada, por trazer novas perspectivas sobre o custo dos direitos. Para os autores, a verdade óbvia é a de que direitos dependeriam do governo, mas a isso deve ser adicionado um corolário lógico, qual seja: os direitos custam dinheiro. A liberdade de contratar gera custos públicos não menos do que o direito à saúde; Segundo Sustein (1999: p. 15) todos os direitos dependem, portanto, do erário público, sejam direitos individuais, ou prestacionais.

Although the cosdiness of rights should be a truism, it sounds instead like a paradox, an offense to polite manners, or perhaps even a threat to the preservation of rights. To 
ascertain that a right has costs is to confess that we have to give something up in order to acquire or secure it. (SUSTEIN, 1999, P:24) 277

No entanto, esta premissa de que todo direito tem valor orçamentário não significa dizer que se deva diminuir o compromisso com a proteção dos direitos fundamentais. Perguntar se os direitos têm custos não implica em perguntar se eles valem a pena. Essa última pergunta deve ser levada para a avaliação política e moral, e não pode ser resolvida sozinha(SUSTEIN, 1999, p: 28).

Segundo Richard Posner, a Análise Econômica do Direito (AED) pode estudada sob dois aspectos, o positivo ou descritivo ou o aspecto normativo ou prescritivo ${ }^{278}$. Poderia o estudo do direito econômico sobrepujar a proteção de direitos fundamentais em detrimento do Direito econômico, como poderia aduzir versão reducionista da Análise Econômica do Direito positiva (COOTER, 1994, P:23) ${ }^{279}$ ?

Neste caso, não se pode conceber as leis ou o direito simplesmente como uma "gigantesca máquina de preços - as leis atuam como preços e impostos que geram incentivos" (VELJANOVSKI, 1994, P:23).

A Análise econômica do Direito tem por precursores a Escola de Chicago que, segundo Edgard Gaston Jacobs (2007, p: 03): “apresenta a microeconomia neoclássica como teoria social.”.

Apresentando esta proposta de Análise Econômica do Direito, Becker, Posner e outros autores perceberam os indivíduos como seres racionais, que almejam a maximização de sua própria satisfação e construíram uma doutrina jurídica onde a eficiência era o valor central.(2006, p: 03)

É preciso ressaltar que a concepção de Economia e Direito pode ser dividida entre as ideias da velha escola de Chicago e a nova. A primeira focalizava no papel da regulação pelas leis e por instrumentos de mercado; e a nova escola, para além desses elementos já citados, observa a influência das arquiteturas e das normas sociais sobre o comportamento dos indivíduos. Para a Nova Escola de Chicago a lei tem papel importante regulando não apenas as ações humanas, mas também os demais elementos reguladores.

\footnotetext{
${ }^{277}$ Tradução livre: Embora o custo dos direitos deva ser um truísmo , soa, em vez como um paradoxo, uma ofensa à maneiras polidas, ou talvez mesmo uma ameaça à preservação de direitos. Para verificar que o direito tem custos é confessar que temos de dar alguma coisa, a fim de adquirir ou prendê-lo.

278 Segundo Posner, a AED no aspecto positivo descreve e analisa a eficácia das normas considerando-se os postulados econômicos; na forma normativa confere um maior valor à eficiência para realizar as modificações no sistema jurídico.

${ }^{279}$ Robert Cooter afirma que a AED positiva pode ter diversas versões, as que mais se destacam seriam a versão reducionista, explicativa e preditiva. A versão reducionista sugere que o Direito possa ser reduzido à Economia, e que categorias jurídicas tradicionais possam ser substituídas por categorias econômicas..
} 
Após a segunda guerra mundial, algumas alterações metodológicas importantes na escola de economia influenciaram uma mudança do projeto jus-econômico. Do ocaso da guerra aos anos 60, Milton Friedmam, George Stigler, Aaron Director e Gary Becker partindo do pensamento do veterano professor de economia de Chicago, Frank Knight, tomaram frente na implementação de uma segunda escola, tanto de pensamento econômico, quando de direito e economia. Estes acadêmicos, apesar da influencia de Knight, um economista avesso aos instrumentos matemáticos e quantitativos, passaram a trabalhar com pesquisas empíricas e tratar o "imperialismo econômico"como um verdadeiro credo. Nesse período surge a Analise Econômica do Direito, como uma outra opção para os acadêmicos de Chicago. (2007, p:04)

A Análise Econômica do Direito, para a Law and Economics, está centrada em três alicerces: na maximização racional da própria satisfação pessoal; as normas legais são preços; e o direito deve ser avaliado sob a perspectiva da eficiência (FILHO, 2007, p: 05).

A maximalização racional concebe que os indivíduos façam escolhas com os maiores benefícios dados menores custos possíveis. Segundo Bruno Samara, essa suposição de maximização racional leva ao processo de "decisão marginalista”. Ou seja, os indivíduos, em suas escolhas, realizarão a próxima unidade de uma dada atividade se, e somente se, os benefícios dessa próxima unidade excederem seus custos (SALAMA, 2008).

A segunda premissa considera a lei como preço em uma concepção meramente utilitarista ${ }^{280}$ de satisfação pessoal. As leis são constrangimentos (preços) que as pessoas pagam se realizam condutas indesejadas. Ao lado em que também são criadas verdadeiras sanções premiais de custo/incentivo. "Esta dicotomia custo/incentivo cria uma estrutura similar ao mercado, onde pessoas decidem suas posturas em face do ordenamento jurídico seguindo a mesma lógica pela qual se posicionam nas questões econômicas.” (FILHO, 2007, p: 05)

A última premissa fundamental da escola de Chicago é a eficiência que, em síntese, significa garantir a maximização de benefícios com o menor custo possível.

\begin{abstract}
Adotando o "ótimo de Pareto" e o critério de Kaldor-Hicks, Richard A. Posner e outros autores buscavam demonstrar que, quando fosse necessário, o direito especialmente, no caso do common law - deveria estimular uma mudança no comportamento das pessoas com objetivo de conduzir a sociedade de uma situação "A", para uma situação "B", com o menor gasto de recursos possível. (FILHO, 2007, p: 05)
\end{abstract}

Segundo a teoria do superior de Pareto tenciona-se chegar a uma situação ótima sem que não haja concomitante piora da situação de outrem, ou ainda, se pessoas eventualmente prejudicadas pudessem ser compensadas por aquelas beneficiadas, segundo critérios orçamentários, financeiros. "Portanto, Posner e seus seguidores expressavam sua eficiência em

${ }^{280}$ O utilitarismo é uma teoria consagrada por Jeremy Bentham e John Stuart Mill, no final do século XVIII e início do século XIX, que , em síntese, prega que os cidadãos cumprem leis e compromissos com nas futuras vantagens (utilidades) que obterão para si e para sociedade. Na visão de Bentham, os cidadãos cumprem as regras com vistas às vantagens utilidades que obterão. Consagrou-se com Stuart Mill, em obra Utilitarismo de 1863. 
termos de maximização da riqueza social, uma espécie de novo valor agregado à ideia de justiça.” (FILHO, 2007, p: 03).

Até que ponto a justiça pode se relacionar com a eficiência? Nos primeiros estudos de Richard Posner a maximização de riquezas servia de substrato para a análise das instituições jurídicas, para a ideia de justiça e do Direito $^{281}$.

O Direito, visto como um sistema de incentivos indutor de condutas, deve promover a maximização da riqueza. Dessa ótica, a pedra de toque para a avaliação das regras jurídicas é a sua capacidade de contribuir (ou não) para a maximização da riqueza na sociedade. Isto leva à noção de que a maximização de riqueza seja fundacional ao Direito, no sentido de que possa ser o critério ético que venha a distinguir regras justas de injustas. (SALAMA, 2008).

Essa subserviência do Direito à economia, enquanto instrumento de maximização de riquezas, ou seja, do papel que a eficiência teria para a ciência do Direito, foi alvo de muitas críticas e o referido autor, após anos de estudo, passou a conceber o tema dentro da perspectiva mais pragmática.

O pragmatismo jurídico de Posner considera que a eficiência não seria critério único e suficiente para os problemas postos no direito. A maximização da riqueza teria que ser encarada sob o ponto de vista mais amplo, em que o Direito é um instrumento para a realização de fins sociais. Para bruno Salama (2008): "Posner postula que o significado das coisas seja social, e não imanente, e que as realizações humanas devam ser apreciadas relativamente às circunstâncias e avaliadas também por suas conseqüências".

O autor teria reconhecido, então, que por mais que se tentasse justificar a defesa das liberdades individuais com base em critérios de eficiência, haveria casos, como por exemplo, a repulsa ao trabalho escravo, à exploração de menores, à tortura, às discriminações raciais, entre outros teriam de ser feitas em outros critérios que não a eficiência, não apenas com base em critérios meramente econômicos.

Segundo Posner, citado por Bruno Salama (2008): “em algum momento mesmo o indivíduo fortemente comprometido com a análise econômica do direito terá que tomar uma posição em questões de filosofia política e de filosofia moral”.

Tal fato conduz ao problema da colisão entre direitos fundamentais. Segundo Robert Alexy o ponto decisivo na distinção entre regras e princípios é que estes são normas que ordenam algo seja realizado na maior medida possível dentro das possibilidades jurídicas e fáticas existentes. São, por conseguinte, mandamentos de otimização, caracterizados por serem

\footnotetext{
${ }^{281}$ Richard Posner tratou dessa hipótese em uma série de artigos da segunda metade da década de 1970, e posteriormente, em 1983, consolidou os escritos em um livro de título "The Economics of Justice".
} 
satisfeitos em graus variados e pelo fato de que a medida devida de sua satisfação não depende somente das possibilidades fáticas, mas também das possibilidades jurídicas. Já a regra vale na exata medida de suas prescrições (ALEXY, 2008, P:90).

No caso da colisão entre princípios, esclarece o autor (2008, P: 94) que:

(...) os princípios têm pesos diferentes e que os princípios com maior peso tem precedência. Conflitos entre regras ocorrem na dimensão da validade, enquanto as colisões entre princípios- visto que só princípios válidos podem colidir- ocorrem, para além dessa dimensão, na dimensão de peso.

Nesse diapasão, o princípio da máxima efetividade dos direitos fundamentais exige que o intérprete faça com que o direito fundamental atinja a sua realização plena. O princípio da máxima efetividade ou da interpretação efetiva tem o condão de conferir à norma constitucional - notadamente em matéria de direitos fundamentais - a interpretação que maior efetividade lhe proporcione, ou seja, que favoreça ao máximo a realização concreta dos propósitos da norma no plano dos fatos (SILVA NETO, 1999, p: 95).

Para garantir a máxima efetividade dos direitos fundamentais de normas sociais, como o Direito à Saúde, a Análise Econômica do Direito deve considerar a implementação das políticas públicas devidas. Portanto, computam-se nos custos do Direito à saúde a sua concretização através de políticas públicas. Nesse sentido, é importante trazer aspectos da teoria da Escola de Direito de New Haven.

A Escola de New haven teve como precursor os estudos de Guido Calabresi em que diferia de alguns pontos dos estudos da Escola de Chicago. A proposta do aludido autor apresenta distanciamento do liberalismo econômico e político presente na Law and Economics.

Susan Rose-Ackerman, afirma que para essa escola a Análise Econômica do Direito serviria para (a) definir a justificativa econômica da ação pública, (b) analisar de modo realista as instituições jurídicas e burocráticas e (c) definir papéis úteis para os tribunais dentro dos sistemas modernos de formulação de políticas públicas(ROSE ACKERMAN, 1999, p: 79).

\footnotetext{
A questão, portanto, não é tanto se eficiência pode ser igualada à justiça, mas sim como a construção da justiça pode se beneficiar da discussão de prós e contras, custos e benefícios. Noções de justiça que não levem em conta as prováveis conseqüências de suas articulações práticas são, em termos práticos, incompletas. Num certo sentido, o que a Escola de Direito e Economia de New havenbuscou é congregar a ética conseqüencialista da Economia com a deontologia da discussão do justo.(SALAMA, 2008)
}

O resultado mais importante levaria à abertura de uma nova janela do pensar, que integra novas metodologias como levantamentos empíricos e estatísticos ao estudo das instituições 
jurídico-políticas, de forma que o Direito pudesse responder de modo mais eficaz às necessidades da sociedade.

E é sobre algumas estatísticas na área da saúde e sobre o seu custeio que se tratará no tópico seguinte.

\section{CONSIDERAÇÕES SOBRE A PROTEÇÃO HISTÓRICA À SAÚdE, A CRIAÇÃo DO SISTEMA ÚNICO DE SAÚDE E DADOS ESTATÍSTICOS DE FINANCIAMENTO DA SAUDE PÚBLICA NO BRASIL}

No final do século XIX, inicio do século XX, do ponto de vista da política de saúde, o Brasil passou por um complexo diferenciado de formas de organização da assistência à saúde. Em primeiro lugar, iniciou-se com o modelo "campanhista" - de inspiração higienista-, seguindo para o modelo médico-assistencial privatista, característico da década de 70, no marco das estratégias de desenvolvimento, culminando no modelo neoliberal que se confronta com o projeto da Reforma Sanitária, no final da década de 80 (PEREIRA, 2008, p: 115).

Em 1982, houve a implantação do PAIS - Programa de Ações Integradas de saúdeque dava ênfase à atenção primária e que tinham pontos programáticos que estariam presentes no SUS.

Ela visava, portanto, a integração das instituições públicas da saúde mantidas pelas diferentes esferas de governo, em rede regionalizada e hierarquizada. Ademais, tinha por propósito criar sistemas de referência e contrarreferência e a atribuição de prioridade para a rede pública de serviços de saúde, com complementação pela rede privada, após sua plena utilização; no mesmo sentido previa, ainda, a descentralização da administração dos recursos;

Outro ponto que serviu de substrato ulteriormente para o SUS foi a simplificação dos mecanismos de pagamento dos serviços prestados por terceiros e seu efetivo controle, a racionalização do uso de procedimentos de custo elevado e o estabelecimento de critérios racionais para todos os procedimentos.(REIS, 2015, p: 33)

Quatro anos depois, foi realizada a Conferência Nacional de Saúde que consagrou o princípio da saúde como direito Universal e dever do Estado. Logo após esta conferência, foram criados os SUDS (Sistemas Unificados e Descentralizados de Saúde) que tinham como principais diretrizes: universalização e equidade no acesso aos serviços de saúde, a integralidade dos cuidados assistenciais, descentralização das ações de saúde, implementação de distritos sanitários. 
Trata-se de um momento marcante, pois, pela primeira vez, o Governo Federal começou a repassar recursos para os estados e municípios ampliarem suas redes de serviços, prenunciando a municipalização que viria com o SUS. As secretarias estaduais de saúde foram muito importantes neste movimento de descentralização e aproximação com os municípios, que recebiam recursos financeiros federais de acordo com uma programação de aproveitamento máximo de capacidade física instalada. Podemos localizar no SUDS os antecedentes mais imediatos da criação do SUS.(REIS, 2015, p:34)

Verificou-se, portanto, que, nas últimas décadas do século $\mathrm{XX}$, houve significativa reestruturação das forças e práticas políticas no Estado Brasileiro, o que cimentou nova consciência de responsabilidade social do Estado, assim como representou o repasse de recursos para os estados e municípios ampliarem suas redes de serviços.

O Movimento da Reforma Sanitária que resultou na Conferência Nacional de Saúde de 1986 propôs a unificação do sistema de saúde e a universalização dos seus serviços, ao contrário do que previa o antigo regime de prestação de assistência médica, o INAMPS. Através deste instituto, o cidadão só gozaria do direito à prestação do serviço de saúde se comprovasse a sua condição de segurado. A amplitude da cobertura ficava restrita às contribuições à Previdência Social.

Esclarece Tânia Maria Marchewka (2008, p:199) que a história sanitária brasileira sintetiza um movimento representativo do que se chamou de verdadeira revolução das relações entre sociedade e Estado, eis que busca principalmente a democratização do acesso à saúde. O processo a que se refere foi denominado de Movimento de Reforma Sanitária, como um movimento em prol da redemocratização do Brasil. Dessa maneira, explica-se que a Reforma Sanitária no Brasil surgiu de um movimento social que reivindicava mudança profunda no modelo assistencial até então implantado no país.

Logo, com a Constituição Federal de 1988, a saúde passa a ser um direito de todos e dever do Estado e fica estabelecido o acesso universal e igualitário aos e serviços a sua promoção, proteção e recuperação. A prestação do serviço público de saúde não fica adstrita ao trabalhador formal, senão a todos os brasileiros considerados como sujeitos de direitos, independentemente de vínculo empregatício.

A saúde subiu sua posição na escala de direitos e passa a ser concebida como um direito fundamental intimamente ligado à dignidade da pessoa humana, fundamento da República Federativa do Brasil (no art. $1^{\circ}$, inciso III). Neste aspecto, para Suelli Dallari, o Direito Sanitário se interessa: 
tanto pelo direito à saúde, enquanto reivindicação de um direito humano, quanto pelo direito à saúde pública: um conjunto de normas jurídicas que têm por objeto a promoção, prevenção e recuperação da saúde de todos os indivíduos que compõem o povo de determinado Estado. (DALLARI, 2008,p: 68)

Esta reformulação ocorreu, no âmbito da Constituição Federal, com a criação do Sistema Único de Saúde (SUS), componente do sistema de Seguridade Social, que é um conjunto integrado de ações de iniciativa dos Poderes públicos e da sociedade, destinado a assegurar os direitos relativos à saúde, à previdência e à assistência social. O sistema tem o caráter universalista e democrático que não está, portanto, vinculado à obrigatoriedade de contribuição.

A Criação do Sistema Único de Saúde (SUS) se deu através da Lei nº 8.080, de 19 de setembro de 1990 - regulamentada pelo Decreto n. 7.508/11- dispõe sobre as condições para a promoção, proteção e recuperação da saúde, a organização e o funcionamento dos serviços correspondentes.

A Primeira lei orgânica do SUS vem detalhar os objetivos e atribuições, os princípios e diretrizes, a organização, direção e gestão, a competência e atribuições de cada nível; a participação complementar do sistema privado; recursos humanos; financiamento e gestão financeira e planejamento e orçamento (REIS, 2015, p: 36).

O Sistema Único de Saúde nasce trazendo um novo conceito do processo saúdedoença e abriga princípios doutrinários da universalidade, equidade e integralidade para o conjunto das ações em saúde que abrangem um ciclo completo e integrado entre a promoção da saúde, a proteção e a recuperação(SUS,1990).

Em seguida, promulga-se a Lei $n^{\circ}$ 8.142, de 28 de dezembro de 1990, que dispõe sobre a participação da comunidade na gestão do SUS e sobre as transferências intergovernamentais de recursos financeiros e institui os Conselhos de Saúde e confere legitimidade aos organismos de representação de governos estaduais.

Os antecedentes do SUS remetem a um cenário epidemiológico e de estrutura sanitária, caracterizada pela falta de cobertura e limitações do modelo vigente, relacionados com os grandes problemas de desenvolvimento e dívida social que o país acumulava. Nesta perspectiva, o SUS promove uma transição de um modelo assistencial, vertical, centrado na doença, baseado na prestação de serviços de saúde individual e notadamente curativo, para um modelo completamente novo quanto à lógica de sua organização e dos valores que os constituem. (PEREIRA, 2008, p.115)

O aludido diploma legal, afinal, fixa ainda os princípios, atribuições, organização, direção e gestão das ações e serviços de saúde executados pelo SUS em relação a cada um dos entes federativos. De modo que a União, os estados, o Distrito Federal e os municípios exercerão, em seu âmbito administrativo, as atribuições que lhe determina a Lei Orgânica de 
Saúde. Neste sentido, a lei determina às direções nacional, estaduais e municipais as competências previstas nos artigos 16, 17 e 18, respectivamente.

A Lei n. 8.080/90, que regula as ações e serviços de saúde, constituiu o SUS, formado por instituições federais, estaduais e municipais. São seus parâmetros, portanto: a descentralização, a direção única e a regionalização.

Verifica-se, portanto, que os princípios organizativos do sistema são a regionalização, a hierarquização (níveis de complexidade crescente em termos da tecnologia e das modalidades de assistência), a resolubilidade, a descentralização (redistribuição de responsabilidades pela diversas esferas de governo), levando ao fortalecimento da municipalização e à participação de políticas públicas por meio dos Conselhos de Saúde e das Conferencias de Saúde que constituem as instancias deliberativas e de pactuação social.(FERREIRA, 2008, p: 115)

Percebe, portanto, que, com o fim do INAMPS, foi possível ampliar a democratização da saúde, no país, tornando-a realmente pública. O sistema de descentralização das políticas públicas, nos municípios, significou maior otimização das ações voltadas para a promoção e atendimento da saúde e direito de qualquer cidadão. Ainda outros fatores foram preponderantes, nesse sentido.

No entanto, a despeito de todo o histórico e evolução normativa e garantista que o sistema de saúde passou nas últimas décadas, estudos têm apontado que a realização da saúde pública no Brasil está muito aquém dos destinatários que dela usufruem.

Portanto, existe uma série de dificuldades pelas quais os gestores de saúde têm passado para garantir a efetividade do direito à saúde, sobretudo em nível local. São as principais dificuldades relacionadas: à insuficiência de recursos; à baixa resolutividade da rede básica de serviços; à deficiência na formação dos profissionais de saúde e à deficiência na gestão dos sistemas locoregionais de saúde.

Isto posto, como garantir o direito ao tratamento adequado quando da omissão do poder executivo? Pode o Poder Judiciário determiná-lo? Quais as disponibilidades orçamentárias de que o Estado dispõe para concretizar tal direito?

\subsection{Dados sobre o financiamento da Saúde Pública no País}

Em que pese a importância dos demais poderes na concretização do Direito sanitário, é papel premente do Poder Executivo elaborar, implementar e executar políticas públicas sanitárias. 
O art. 198, $\S 1^{\circ}$ aduz que o sistema único de saúde será financiado, nos termos do art. 195, com recursos do orçamento da seguridade social, da União, dos Estados, do Distrito Federal e dos Municípios, além de outras fontes, dentre as quais se incluem as contribuições de ordem privada. Assim são as diretrizes constitucionais de repartição do financiamento pelos entes federativos.

a) o Sistema Único de Saúde, de acesso universal, financiado exclusivamente com recursos públicos ; b) o segmento de planos e seguros privados de saúde, de vinculação eletiva, financiado com recursos das famílias; c) o segmento de atenção aos servidores públicos, civis e militares e seus dependentes, de acesso restrito a essa clientela, financiado com recursos públicos e dos próprios beneficiários; e d) o segmento de provedores privados autônomos de saúde, de acesso direto, mediante pagamento no ato.(ALVES, 2013, p. 91) ${ }^{282}$

Neste sentido, deve-se esclarecer que a base de financiamento da seguridade social inclui as contribuições dos empregados e empregadores, bem como fontes de contribuições específicas, tais quais: a contribuição para o Financiamento da Seguridade Social (COFINS), a Contribuição sobre o lucro Liquido das empresas (CSLL). Depende ainda dos orçamentos da União, dos Estados e dos Municípios e, em alguns casos da iniciativa privada, portanto tem pluralismo institucional.

Nos países desenvolvidos, tomando como exemplo os países da OCDE, a participação das fontes públicas no financiamento do sistema representa, em média, $70 \%$ do gasto total, variando de $67,5 \%$ (Austrália) a $84,1 \%$ (Noruega). Os Estados Unidos são uma exceção importante a essa regra por terem um gasto público inferior a $50 \%$ do total (WHO, 2010). No Brasil, com base em dados de 2007, o gasto público é inferior 3,5\% do PIB e, de acordo com estimativas apresentadas na ContaSatélite de Saúde (IBGE, 2009), a participação das fontes públicas nos gastos totais com saúde foi $42 \%$ em 2007, sendo, possivelmente, o único país com sistema universal de saúde, ao menos do ponto de vista legal, onde o gasto privado é maior que o público (ALVES, 2015, P: 92).

Neste sentido, a fonte de custeio privada merece destaque. O artigo 199 da Constituição Federal reza que a assistência á saúde é livre á iniciativa privada e que a participação privada no SUS pode ser realizada de forma complementar, mediante contrato de direito público ou convênio, tendo como preferência as entidades filantrópicas e as sem fins lucrativos. $\mathrm{O}$ art. 3 do Decreto 7.508/11 também traz a previsão de financiamento da saúde pela iniciativa privada.

\footnotetext{
${ }^{282}$ Ainda torna-se necessário analisar o financiamento indireto a partir de isenções concedidas às instituições sem fins lucrativos, as deduções no imposto de renda concedidas às pessoas físicas e jurídicas devido a gastos com médicos, laboratórios, hospitais e planos de saúde e a desoneração tributária. Outra forma de subsídio público indireto à atividade privada ocorre quando o SUS atende a pacientes que são usuários de planos e seguros de saúde, e não é ressarcido pelos serviços prestados, o que conduz a aumento do deficit orcamentário do sistema de saúde.
} 
Percebe-se que a parcela de contribuição da iniciativa privada tende a ser de forma complementar nos casos em que haja insuficiência da capacidade instalada no setor público, em determinadas áreas, como deixou explicitada a Lei Orgânica do SUS, no art. 24.

A participação privada contribui para aumentar a capacidade de prestação de serviços pelos SUS sem que isso signifique um aumento nos gastos públicos com saúde.

\begin{abstract}
O setor privado proporciona nada menos que 57,6\% do total de leitos que podem ser usados por pacientes dos SUS. O segmento privado sem fins lucrativos contribui com $37,2 \%$ do total de leitos, enquanto o segmento com fins lucrativos tem uma participação bem menor, 20,4\%. Tal proporção parece corresponder à diretriz de que o gestor do SUS deve priorizar, sempre que possível, a parceria com instituições nãolucrativas.(PEREIRA, 2008, p:119)
\end{abstract}

De tal sorte que a vinculação da prestação de serviços de saúde não está ligada essencialidade de terem os prestadores de serviço à mesma natureza jurídica, senão a de que existe gestão unificada dos serviços públicos relativos ao direito à saúde. "Portanto, o SUS é único na medida em que, devido a seu comando único nos diversos níveis de governo, é capaz de pôr em ação políticas de saúde e de gestão que preservam o interesse público.” (PEREIRA, 2008, p:119)

Ainda assim, com essa estruturação o SUS deveria dar cobertura a todos, o que na prática não ocorre. Neste sentido, "as despesas inerentes ao financiamento do sistema de saúde brasileiro absorvem 9,7\% das rendas das famílias" (BARBOSA, 2008,p:. 283).

De sorte que ao lado das contribuições fiscais, e dos orçamentos destinados aos gestores federal, estaduais e municipais, e da iniciativa particular complementar aos SUS como forma de prestar assistência efetiva aos cidadãos, ainda assim a esfera privada contribui com gastos referentes à renda per capita da família.

Superado esse aporte com relação ao custeio dos serviços de saúde pelos particulares, importa destacar a participação financeira dos gestores municipais, estaduais e federal. Neste sentido, esclarece Swedenberger Barbosa (2008, p:284):

As hipóteses para o financiamento da saúde foram objeto de estudo pelo Ministério
da Saúde em 2004, a saber: na primeira hipótese considerou-se que os recursos seriam
reajustados anualmente, de acordo com a variação nominal do PIB (algo em torno de
$2 \%$ ao ano). Na segunda hipótese, estimou-se alcançar um sonho antigo de a saúde
ficar com $30 \%$ do orçamento da Seguridade Social. A terceira hipótese, como base no
que consta da emenda constitucional (EC n. 29), o gasto federal com a Saúde seria de
aproximadamente R $\$ 81$ bilhões, ou 4,4\% do PIB ou mais do que o dobro do que se
gasta anualmente.

$\mathrm{O}$ art. 55 da ADCT previu que até que fosse aprovada a LDO, trinta por cento, no mínimo, do orçamento da seguridade social, excluído o seguro desemprego deveriam ser 
destinados ao setor de saúde. Esta determinação constitucional não foi cumprida a contento nos primeiros anos da década de $90(2008, p \text { : 284 })^{283}$.

Esse fato agravou a situação de incerteza e de instabilidade do financiamento da saúde (MENDES; MARQUES, 2009). A perda dos recursos que vinham da Previdência Social, associada à política de ajuste fiscal promovida pelo Governo Federal no ano de 1994 (UGÁ; MARQUES, 2005), fez o Ministério da Saúde buscar empréstimos junto ao Fundo de Amparo ao Trabalhador (FAT ) e iniciar penoso processo no Congresso Nacional para aprovar um tributo adicional, vinculado à saúde e posteriormente também à previdência social: a Contribuição Provisória sobre Movimentação Financeira (CPMF).

A cobrança da CPMF começou a ser realizada em 1997 e findou em 2007, tendo sido responsável por 1/3 do total de recursos do Ministério da Saúde. De sua provisoriedade decorreu a necessidade de medidas mais efetivas, a partir do qual adveio a EC 29/2000, dotada de normas auto aplicáveis, que acrescentou o art. 77 à $\mathrm{ADCT}^{284}$ o qual:

assegurou a participação das três esferas de governo no financiamento das ações e serviços públicos de saúde, a partir da definição de um aporte anual mínimo de recursos. No caso da União, os recursos a serem aplicados em 2000 seriam o montante empenhado no exercício de 1999 acrescido de, no mínimo, 5\%. A partir daí, o valor mínimo seria apurado no ano anterior e corrigido pela variação nominal do PIB. Os estados e o Distrito Federal deveriam aplicar, no mínimo, $12 \%$ da receita própria ao passo que os municípios deveriam aplicar 15\%, e, em 2000, o percentual mínimo a ser aplicado seria de 7\% para esses entes da federação.(ALVES, 2015, p. 95)

A Resolução 322 do CNS regulamentou algumas diretrizes acerca da aplicação da EC n $29 / 2000$, dentro outros da base de cálculo para definição dos recursos mínimos a serem aplicados em saúde para a União, Estados, Municípios e DF. O aumento no financiamento da saúde pública foi significativo, sobretudo relativamente ao municípios, mas poderia ter sido ainda maior se as diretivas da Resolução da CNS fossem fielmente seguidas.

Com a EC 29, o gasto público com saúde saiu de R \$ 64,8 bilhões, em 2000, para R\$ 138,7 bilhões, em 2010, em termos reais. Como desdobramento, o gasto per capita das três esferas com o SUS passou de R $\$ 378,27$, em 2000, para R \$ 717,70, em 2010,

\footnotetext{
283 O financiamento e a transferência de recursos federais para os estados e municípios, com o respectivo monitoramento e controle, passaram a ser regulamentados pela portaria GM/MS n. 204, de 29 de janeiro de 2007. Os recursos foram organizados e transferidos na forma dos blocos de financiamento. Os blocos são: I) Atenção Básica; II) Atenção de Média e alta complexidade Ambulatorial e Hospitalar; III) Vigilância em Saúde; IV) Assistência Farmacêutica e V) gestão do SUS.

${ }^{284}$ Art. 77. Até o exercício financeiro de 2004, os recursos mínimos aplicados nas ações e serviços públicos de saúde serão equivalentes: I - no caso da União: a) no ano 2000, o montante empenhado em ações e serviços públicos de saúde no exercício financeiro de 1999 acrescido de, no mínimo, cinco por cento; b) do ano 2001 ao ano 2004, o valor apurado no ano anterior, corrigido pela variação nominal do Produto Interno Bruto - PIB; II - no caso dos Estados e do Distrito Federal, doze por cento do produto da arrecadação dos impostos a que se refere o art. 155 e dos recursos de que tratam os arts. 157 e 159, inciso I, alínea a, e inciso II, deduzidas as parcelas que forem transferidas aos respectivos Municípios; e III - no caso dos Municípios e do Distrito Federal, quinze por cento do produto da arrecadação dos impostos a que se refere o art. 156 e dos recursos de que tratam os arts. 158 e 159 , inciso I, alínea b e $\S 3^{\circ}$.
} 
apresentando crescimento real de $89,73 \%$ no período. Em relação ao PIB, o gasto do SUS passou de 2,89\%, em 2000, para 3,77\%, em 2010. .(ALVES, 2015, p. 96)

Convém lembrar também que foi criado, em 1999, o Sistema de Informação do Orçamento Público de Saúde, (SIOPS) que consistiu em um importante avanço para a organização dos gastos públicos, registra o orçamento com saúde nas três esferas de gestão como mecanismo que visa assegurar recursos mínimos para a promoção da saúde para a população. Neste mesmo caminho foi promulgada a Emenda constitucional 29 que alterou os arts. 34, 35, 156, 160, 167 e 198, todos da Constituição Federal.

Nesse sentido, com base nos dados declarados ao SIOPS - para constatar se as aplicações estavam de acordo com o estabelecido na Resolução 322 do CNS- percebeu-se que nem sempre o Ministério da Saúde teria cumprido a Emenda 29, no período 2000 a 2008, o déficit de aplicação teria sido de R \$ 3,08 bilhões.(ALVES, 2015, p. 97). Isso significa apenas um dos exemplos a ser dado relativamente à gestão deficiente das políticas e leis de financiamento da saúde pública no país.

A Lei complementar 141/12 regulamentou a EC 29/00 o que significou mudanças nos procedimentos hoje adotados pelos entes federados. A lei complementar é aplicável em todo o território nacional, desta forma, a norma contribuirá para reduzir a subjetividade que durante anos permeou a definição de ações e serviços para fins de cômputo no piso constitucional da saúde e aproximará as despesas com saúde da intenção original do constituinte da EC nº 29, de $2000^{285}$. É o que se espera.

\section{O PAPEL DOS AGENTES CONCRETIZADORES DO DIREITO À SAÚDE}

Verificou-se, nos tópicos anteriores, a importância da AED. Mas de fato poderia a eficiência ser igualada à ideia de justiça? Conforme visto, a partir das ideias da Escola de New haven da teoria do Superior de Pareto, a construção da justiça se beneficiar da discussão dos custos e benefícios. Isto é inegável, mas a eficiência não se iguala à justiça que se pretende no caso do Direito à saúde.

\footnotetext{
${ }^{285}$ Neste contexto, é relevante destacar também, para efeitos de discussão dos limites orçamentários, a importância das NOBs (Normas Operacionais Básicas) dos anos de 1991-1993 e a de 1996. Elas foram instrumentos fundamentais no relativo à estruturação e ao fortalecimento das capacidades administrativas e institucionais dos órgãos gestores nas três esferas, para o exercício de novas atribuições. Elas estabeleceram critérios e mecanismos de transferências de recursos federais como indutores da reorganização do sistema, atuando como redefinidores da repartição de atribuições e competências e do grau de autonomia /capacidade gestora de cada Estado e município. (PEREIRA, 2008, p.120).
} 
A Análise Econômica do Direito, no caso do Direito à saúde, pode ser realizada utilizando os aspectos econômicos que podem garantir uma maior eficiência para se atingir a máxima efetividade deste direito fundamental, utilizando-se igualmente de temperamentos e da ponderação de interesses.

Assim, se o Estado brasileiro tem à sua disposição o incremento do quantitativo total dos recursos públicos destinados à área de saúde, levando em conta os gastos de ordem privada. Tendo como substrato tais informações é que se passa a questionar: como garantir a efetividade e aplicação imediata à norma de direito à saúde- respeitada a isonomia, o acesso universal e o orçamento destinado pelo Estado?

Segundo Gustavo Amaral (2001, p: 136) a questão da escassez de recursos públicos se coloca de maneira especial no acesso à saúde. Algumas pessoas podem pensar que quando a saúde e a vida estão em jogo, qualquer referência a custo é repugnante, ou até imoral. Mas o aumento, do custo com tratamento tomou essa posição insustentável.

Neste sentido, quando o Estado determina a aplicação em determinada área, segundo o autor, significaria que teria que reduzir o montante em outra. Isso, por sua feita, traria como consequência a desorganização da Administração Pública. O Estado tem de custeá-lo e por vezes, retiraria tais recursos que seriam destinados a outros pacientes. Implicaria em atender ao jurisdicionado individualmente em detrimento da promoção da saúde pública globalmente considerada.

E continua afirmando que existem menos recursos do que o necessário para o atendimento das demandas e que a escassez não seria acidental, mas essencial(AMARAL, 2001 p: 147). As decisões alocativas seriam escolhas trágicas(CALABRESI, 1998), tendo em vista que, em última instância, implicariam na negação de direitos que, no campo da saúde, poderiam redundar em sofrimento, ou até em situação pior: na morte.

\footnotetext{
Esse caráter disjuntivo das escolhas traz, muitas vezes, uma teia de consequências, uma cadeia de ações e reações que não conseguem ser sequer imaginadas dentro da ótica estrita da microjustiça,e que só vem sendo abordada há poucos anos. Tome-se como exemplo a regulação do risco. Não raro, a diminuição de um risco à saúde gera simultaneamente o aumento de outro risco(...) A decisão de proteger vim dado interesse muitas vezes gera novas formas de ameaça, tomando as decisões alocativas ainda mais complexas. (AMARAL, 2001 p: 147).
}

De fato, os recursos orçamentários não são ilimitados e a sua alocação depende de que sejam realizadas escolhas. Todavia, o grande problema do país é a má gestão dos recursos públicos que apesar de finitos podem, se bem geridos, tornar-se suficientes para garantia da 
saúde e vidas de muitas pessoas, seja no aspecto individual por meio da microjustiça, seja através da macrojustiça.

O ativismo judicial consiste, em modo específico que os Juízes e Tribunais têm de interpretar e aplicar os ditames constitucionais, expandindo o seu sentido e alcance para a proteção do ordenamento jurídico, e principalmente a realização da proteção de Direitos. O Poder judiciário,consonante com os ideais de um Estado Democrático de Direito, tem que ser órgão distributivo aplicador do direito material.

A ideia de ativismo judicial está associada a uma participação mais ampla e intensa do Judiciário na concretização dos valores e fins constitucionais, com maior interferência no espaço de atuação dos outros dois Poderes.

$\mathrm{O}$ ativismo judicial exige que os juízes sejam atuantes e façam cumprir materialmente a lei. Essa atuação judicial tem de estar pautada na interpretação e equalização de princípios constitucionais, como a dignidade da pessoa humana.

\begin{abstract}
O direito à Saúde é outro cuja a concretização, em grande parte está a depender do aplicador e do operador do direito que não se dissocia do princípio da máxima efetividade (...) A norma constitucional dita programática é suficiente para impor à Administração uma conduta que não seja dessonante da previsão normativa, servindo também de um manancial teleológico dirigente da sociedade política, não se devendo esquecer, em absoluto que dentre os fundamentos do Estado brasileiro está incluído a dignidade da pessoa humana (art. $1^{\circ}$, III).(SILVA NETO, 1999, p:99)
\end{abstract}

Como se não bastassem esses argumentos retirados da Análise Econômica do Direito, a Constituição Federal, demais leis como a lei $\mathrm{n}^{\circ}$ 8.080/90, determinam que o aporte de recursos privados seja feito de modo complementar e no Brasil, a os gastos de ordem privada superam os públicos. Percebe-se, portanto, um flagrante desrespeito aos imperativos da Constituição Federal, esvaziando sua força normativa, unidade e máxima efetividade dos direitos fundamentais sociais.

É dever do Poder Judiciário garantir não só o acesso à justiça, mas de ser guardião da própria Constituição Federal, lei máxima do sistema. Estas prestações, com maior razão, devem cuidar dos limites essenciais para a proteção da vida humana. É o direito à obtenção de prestações públicas de saúde que garantam as condições de subsistência. O Estado, nas três esferas de poder, está vinculado à proteção do Direito à vida/saúde através as prestações existenciais essenciais, escolhendo um meio cabível que melhor torne tal direito possível.

Não de prestações materiais sofisticadas, posto que é preciso igualmente racionalizar, senão daquelas prestações realmente essenciais para um padrão mínimo de vida digna. A suposta limitação fático-orçamentária alegada pelo Estado em sua defesa deve ser, em muitos 
casos, relativizada em respeito ao principio basilar da dignidade da pessoa humana, sem o qual a pessoa não se realizar em sua condição de humanidade.

O art. 198 da Constituição Federal determina o financiamento da Saúde pública com recursos provenientes das contribuições da Seguridade Social (COFINS E CSLL), da União, Estados, Distrito Federal e Municípios, com a atividade complementar da iniciativa privada, seja através dos planos de saúde seja através das contribuições diretas.

Apesar do quantitativo destinado à saúde, no valor da dotação atualizada, no $1^{\circ}$ bimestre do ano de 2015, na União, remonta o impressionante cifra ${ }^{286}$ de $\mathrm{R} \$ 108.780 .672 .061,00$ que tem por fonte demonstrativos do Ministério da Saúde, alega-se que os recursos são escassos para atender todas as necessidade da sociedade.

Como foi visto, no capítulo anterior, dados sobre o financiamento da saúde pública nos países desenvolvidos chegam, via de regra, ao custeio público de $70 \%$. Apenas se têm como exceção os Estados Unidos da América que contribuem com 50\% do aporte de recursos para a saúde.

Como reforço argumentativo é preciso ressaltar entrevista realizada pela Região e Redes com Luis Eugênio Portela, presidente da Associação Brasileira de Saúde Coletiva (Abrasco) e professor do Instituto de Saúde Coletiva (ISC-UFBA), que aponta a relação entre os subsídios privados e públicos no financiamento da saúde pública brasileira, e considera que:

O desafio para superar o subfinanciamento do SUS (3,5\% ou $4 \%$ do PIB) passa, portanto, por extinguir, ainda que progressivamente, os subsídios ao setor privado. A experiência dos países com sistemas universais demonstra que os gastos públicos devem ser superiores a, pelo menos, $75 \%$ do total de gastos em saúde. ${ }^{287}$

No Brasil, a fonte pública corresponde a $42 \%$ dos recursos destinados à saúde. Quarenta e dois por cento. Ou seja, o gasto privado com a saúde que, segundo o art. 199 da Constituição Federal de 1988 seria complementar ao público corresponde não menos do que 57\% do financiamento da saúde.

\footnotetext{
286 Dados coletados do site do Ministério da Saúde referentes ao Relatório Resumido da Execução Orçamentária da União: Demonstrativo das Despesas com Ações e Serviços Públicos de Saúde Orçamento Fiscal e da Seguridade Social do primeiro bimestre de 2015. Disponîvel em: < http://siops.datasus.gov.br/msu_rreo.php?acao=a\&ano=2015\&periodo=1\&desc $=1 \%$ BA\%20Bimestre $>$. Acesso em: 30 de jul. 2015.

${ }^{287}$ Entrevista publicada m 13 de agostos de 2014 no site Região e Redes, um caminho para universalização da saúde no país, com Luis Eugênio Portela, presidente da Associação Brasileira de Saúde Coletiva (Abrasco) e professor do Instituto de Saúde Coletiva (ISC-UFBA). Disponível em: < http://www.resbr.net.br/o-direito-plenoa-saude-sera-fruto-de-mobilizacao-popular/>. Acesso em: 29 de Jul. 2015.
} 
Os gestores de saúde têm levado mais que à literalidade o art. 24 da lei $\mathrm{n}^{\circ}$ 8.080/90 que afirma que quando as suas disponibilidades forem insuficientes para garantir a cobertura assistencial à população de uma determinada área, o SUS poderá recorrer aos serviços ofertados pela iniciativa privada. Nesse sentido, 9,7\% da renda per capita das famílias, sem considerar o pagamento dos impostos, é destinada para a saúde, dentre os quais 35,8\% correspondem ao custeio dos planos privados de saúde e $64,2 \%$ de pagamento direto. E neste contexto o financiamento público da saúde tem sido aquém do que se propõe a legislação ordinária e a Constituição Federal.

A EC 29/00 significou uma reformulação no custeio da saúde, mas ainda assim não foi implementada a contento e as diretrizes estipuladas pela Resolução 322 do CNS geraram um déficit de aplicação de $\mathrm{R} \$ 3,08$ bilhões de reais.

Estudos mostram que o gasto com liminares de medicamentos dadas pelo Poder judiciário corresponderam ao quantitativo de R $\$ 132$ milhões de reais em 2010 (BASSET, 2011). Este quantitativo responde por $4,4 \%$ deste total que não foi sequer implementado. Esse é só um exemplo dentro do quantitativo enorme de casos de má gestão pública do dinheiro alocado ou que deveria ter sido alocado para a saúde.

\section{CONSIDERAÇÕES FINAIS}

A Constituição Federal consiste na expressão máxima do Estado Democrático de Direito brasileiro, seus comandos devem ser respeitados e materialmente concretizados, mormente no que pertine aos direitos fundamentais. São fundamentais também, no seu aspecto material, quando contêm decisões fundamentais sobre a estrutura do Estado e da sociedade, quando considera a dignidade da pessoa humana.

Nesse sentido, pergunta-se: seria realmente lícito deixar de atender as microlides levadas ao Judiciário por conta de um pretenso resguardo á macrojustiça distributiva?

A versão mais recente da AED, do pragmatismo jurídico de Posner considera que a maximização de riquezas sociais não pode ser realizada apenas sob o ponto de vista meramente econômico. Do mesmo modo, não se pode cogitar que as leis sejam apenas preços; e a escola de New haven também trata do papel importante das políticas públicas. 
Também não se pode olvidar que, no ano de 2013, criou-se o Movimento Saúde $+10^{288}$ que realizou um abaixo-assinado para o PL 321/13 que obrigava a União a destinar, no mínimo, $10 \%$ das receitas correntes brutas para a saúde pública. É o reflexo de que a participação popular é de extrema valia para a discussão e mudanças que precisam ser realizadas no país.

Nesta linha de intelecção, importantíssimo trazer as ideias de Peter Haberle para quem a teoria da interpretação constitucional sempre esteve muito vinculada a modelo de interpretação de sociedade fechada. Ela reduz, ainda, seu âmbito de investigação, na medida em que se concentra, primariamente, na interpretação constitucional dos juízes e procedimentos formalizados , segundo Haberle, a interpretação constitucional tem que ser cada vez mais pluralista.

Mas para o desenvolvimento realista e uma interpretação constitucional devem ser considerados

A mobilização popular do Movimento 10+é representação fiel de que a sociedade civil pode ser intérprete jurídico das normas e ainda mais, demonstra o exercício da democracia participativa que pode ser realizada inclusive por meio da iniciativa de Ação Popular. Cumprindo os fundamentos da cidadania, pluralismo político e, em especial, da dignidade da pessoa humana.

A dignidade da pessoa humana deve ser concebida de maneira mais abrangente possível, não basta, porém, a liberdade formalmente reconhecida, pois a dignidade da pessoa humana, como fundamento do Estado Democrático de Direito, reclama condições mínimas de existência, existência digna conforme os ditames de justiça social.

Incumbe ao Poder Executivo a realização das políticas públicas devidas, realizando uma política alocativa de recursos, fazendo-se cumprir, a contento, regulamentos, as leis, a Constituição; ao legislativo ouvir aos clamores populares, discutir os projetos de lei de interesse social de maneira.

Cabe ao Judiciário, utilizando-se da ponderação, dos elementos interdiciplinares, principalmente o uso racional de recursos preconizados pela Análise Econômica do Direito, garantir a maior efetividade de direitos com o mínimo de sacrifícios, enquanto garante da Constituição, coibir e regular a atuação ou omissão dos demais poderes, ou seja, de seus eventuais excessos e faltas;

\footnotetext{
288 Movimento popular que visou, no ano de 2013 a coleta de assinaturas para um Projeto de Lei de Iniciativa Popular que assegure o repasse efetivo e integral de $10 \%$ das receitas correntes brutas da União para a saúde pública brasileira, alterando, dessa forma, a Lei Complementar no 141, de 13 de janeiro de 2012. Disponível em: http://www.saudemaisdez.org.br/index.php/2012-10-10-19-14-46/manifesto. Acesso: 30 de agosto de 2015.
} 
E é dever dos cidadãos, em seu papel igual de intérpretes da Constituição, velar pelo seu cumprimento, velar pela dignidade de todos.

A tarefa parece utópica e de fato é hercúlea, no entanto, todos são responsáveis por realizar o Direito à Saúde. A discussão e problematização da questão já significam grande passo.

\section{REFERENCIAS}

ALEXY, Robert. Teoria dos direitos fundamentais. Trad. Virgílio A. Da Silva. São Paulo: Malheiros, 2008.

ALVES, SANDRA MARA; DELDUQUE, Maria Célia; NETO, Nicolao. (orgs.) Direito Sanitário em perspectiva. Brasília: ESMPU: Fiocruz, 2013. Disponível em: < http://escola.mpu.mp.br/linha-editorial/outras publicacoes/DireitoSanitarioEmPerspectiva.pdf>. Acesso em: 25 de jul. 2015.

AMARAL, Gustavo. Direito, escassez e escolha. Rio de Janeiro: Renovar, 2001.

BARBOSA, Swedenberger. Financiamento da saúde: Ferramenta de concretização do Direito à saúde. In: COSTA, Alexandre Bernardino ... [ et al.] (orgs). O direito achado na rua: Introdução crítica ao direito à Saúde. Vol. 4. Brasília: CEAD/ UNB, 2008, p. 281- 290.

BARROSO, Luis Roberto. Da falta de efetividade a judicialização efetiva: Direito à saúde, fornecimento gratuito de medicamentos e parâmetros para a atuação judicial. Disponível em: <http://www.migalhas.com.br/dePeso/16,MI52582,81042>. Acesso em 25. Jul. 2015.

BASSETTE, Fernanda. Gastos do governo com remédios via ação judicial cresce $5000 \%$ em 6 anos. O Estado de São Paulo, Vida, Saúde. São Paulo, 28 abr. 2011. Disponível em: < http://www.estadao.com.br/noticias/geral,gasto-do-governo-com-remedios-via-acao-judicialcresce-5000-em-6-anos-imp-,711740>. Acesso em: 27 de jul. 2015.

BRASIL . SUS. Ministério da Saúde. ABC do SUS Doutrinas e Princípios. Secretaria Nacional de Assistência à Saúde. Brasília, 1990.

CALABRESI, Guido; and BOBBIT, Philip. Tragic Choices - The conflicts society confronts in the allocation of tragically scarce resources. Norton, New York, 1978. 
COOTER, Robert. "Law and the Imperialism of Economics: An Introduction to the Economic Analysis of Law and a Review of the Major Books". UCLA Law Review, v. 29, 1982.

DALLARI, Sueli. O conteúdo do direito à saúde. In: COSTA, Alexandre Bernardino, et al. (org). O direito achado na rua: Introdução crítica ao direito à Saúde. Vol. 4. Brasília CEAD/ UNB, 2008, p. 91-102.

FILHO, Edgar Gaston Jacobs Flores. (2007). A NOVA ESCOLA DE CHICAGO E AS MODALIDADES DE REGULAÇÃO: Tendências do Law and Economics e aplicações para o direito brasileiro. Berkeley Program in Law \& Economics. UC Berkeley: Berkeley Program in Law and Economics. Disponível em: <https://escholarship.org/uc/item/1fm5r7xh>. Acesso em: 26 de julho de 2015.

HABERLE, Peter. Hermenêutica constitucional: a sociedade aberta dos intérpretes da Constituição -contribuição para a interpretação pluralista e "procedimental" da Constituição. Porto Alegre: Sérgio A. Fabris, Editor, 1997.

HESSE, Konrand. A força normativa da constituição. Tradução de Gilmar Ferreira Mendes. Porto Alegre: Sérgio A fabris, Editor, 1997, 2002.

LEITE, Cláudia. Políticas Públicas De Saúde Da População Negra. Disponível em: <http://www.claudialima.com.br/pdf/politicas_publicas_de_saude_da_populacao_negra.pdf.> . Acesso em: 04 de jul de 2015.

MARCHEWKA, Tânia. Saúde mental no contexto sanitário. In: COSTA, Alexandre Bernardino ... [ et al.] (org). O direito achado na rua: Introdução crítica ao direito à Saúde. Vol. 4. Brasília. CEAD/ UNB, 2008. p. 187-214.

PEREIRA, Marcio. O Sistema Único de Saúde, uma retrospectiva e principais desafios. In: COSTA, Alexandre Bernardino ... [ et al.] (org). O direito achado na rua: Introdução crítica ao direito à Saúde. Vol. 4. Brasília. CEAD/ UNB, 2008. p. 113-126.

REIS, Denizzi de Oliveira; ARAÚJO Eliane Cardoso; CECÍLIO Luiz Carlos de Oliveira. Políticas Públicas de Saúde no Brasil: SUS e Pactos pela Saúde. Disponível em: <http://www.unasus.unifesp.br/biblioteca_virtual/esf/2/unidades_conteudos/unidade04/unidad e04.pdf $>$. Acesso em: 10 de jul de 2015.

ROSE-ACKERMAN, Susan. Law and Economics: Paradigm, Politics, or Philosophy, 1989, apud MERCURO, Nicholas e MEDEMA, Steven G. Economics and the Law - From Posner to Post-Modernism. Princeton: Princeton University Press, 1999. 
SALAMA, Bruno Mayerhof. O que é pesquisa em direito e economia? Cadernos Direito GV. São Paulo, estudo 22, v. 5, n. 2, 2008. Disponível em:

<http://www.direitogv.com.br/interna.aspx. $>$. Acesso em: 24 de julho de 2015.

SILVA NETO, Manoel Jorge e. O Princípio da Máxima Efetividade e a Interpretação Constitucional. São Paulo: LTR, 1999.

SUNSTEIN, Causs and HOLMES, Stephen. The cost of rights. Why liberty depends on taxes. Cambridge: Harvard University Press, 1999.

VELJANOVSKI, Cento. A Economia do Direito e da Lei-uma introdução. Francesco J. Beralli (Trad.) Rio de Janeiro: Instituto Liberal, 1994.

\title{
CONSIDERATIONS ON ECONOMIC ANALYSIS OF LAW AND THE LAW EFFECTIVENESS FUNDAMENTAL TO HEALTH IN BRAZIL
}

\begin{abstract}
This article aims to analyze what would be the means to ensure the effectiveness of the Fundamental Right to Health in Democratic rule of Brazilian Law. How social rights of health are implemented in accordance with the prevailing constitutional values? More than mere limitation of political power, the constitutionalism ensures axiological feature rights, giving them fundamentality material and having as north first to human dignity. Besides, this study holds up the detail of the right to health. What are the essential characteristics of structure and operation? The creation of the National Health System favored the implementation of an equitable health system, non-contributory and universal access. This audacious task requires a number of legal instruments, judicial and extrajudicial to be held. Ensuring effectiveness of this right requires positive benefits of the state and the consequent implementation of appropriate public policies, however, there are some limits, among them stand out, especially the budget order, which must be evaluated. The social and economic cost of these demands and also the possibility of applying unions and judicial solutions are key points to meet the needs of the recipients of the health system. The Law and Economics also serves as the foundation for the pursuit of the implementation and effectiveness of this right.
\end{abstract}

Keywords: Right to Health. Law and Economics. Human Dignity. Effectiveness. 